\title{
INVESTIGATIONS OF BIOGAS PRODUCTION POTENTIAL FROM GRASS HAY PELLETS
}

\author{
Vilis Dubrovskis, Imants Plume, Indulis Straume \\ Latvia University of Life Sciences and Technologies, Latvia \\ vilisd@inbox.lv, imants.plume@inbox.lv, indulis.straume@1lu.lv
}

\begin{abstract}
There are large agricultural land areas overgrown with grasses and not used for agricultural production or having protective environmental status in Latvia. Grass biomass from those areas can be utilised for biogas production, however, the most of abandoned lands are located far from the existing biogas plants and high transportation expenses is often the limiting factor for usage of the grass biomass for biogas production. This problem can be solved by production of grass pellets, having low moisture content (8-12\%), high density and high dry organic matter (DOM) content. Such grass pellets production can be provided on relatively small equipment with the size adapted to the local grass biomass resources. After production, grass pellets can be transported to biogas plants with minimal transport expenses, so providing additional supply of valuable biomass to biogas plants for stable round year biogas production. Investigation of biogas potential from grass hay pellets was carried out using the laboratory facilities. The grass hay pellets were fermented anaerobically in 16 bioreactors operating in batch mode at temperature $38^{\circ} \mathrm{C}$. On average, $0.666 \mathrm{l} \cdot \mathrm{g}^{-1}$ DOM biogas $\left(0.355 \mathrm{l} \cdot \mathrm{g}^{-1}\right.$ DOM methane) was obtained during 46 days of the anaerobic digestion period. Investigations show that high specific methane yield can be obtained from the grass hay pellets, and its utilisation in biogas plants can be useful taking in account the high content of dry organic matter in the initial biomass. The second study deals with investigation of the methane yield obtainable from co-digestion of the grass hay pellets with sunflower oil and molasses. Addition of sunflower oil increases the methane yield by $28.8 \%$ and addition of molasses increases the methane yield by $8.8 \%$.
\end{abstract}

Key words: hay, anaerobic digestion, methane.

\section{Introduction}

According to the renewable energy action plans of the member states of the European Union, the share of bioenergy $36 \%$, including energy from solid biomass $54.5 \%$, is the largest contribution in renewable energy targets for 2020 [1]. Since the modern society will move towards a low-carbon economy after 2020 or rather towards a bio-economy based on the cascade principle, more biomass will be used for non-energy based purposes, and this requires an effective energy recovery from waste biomass, e.g. for heat production, because the high value biomass will be used for food or feed purposes.

The intelligent use of bio-energy will be integrated with other renewable energy sources and organic products, recognizing that wind, solar and bioenergy are complementary energy areas, in order to achieve $100 \%$ renewable heat and power production by the end of the century [2]. Two of the most commonly available residue biomass types in urban areas across Europe are grasses and leaves. In Germany in 2009, it was estimated that biomass potential from the green barrier zones is equal to one million tonnes fresh substances (FM) and its use was proposed for the production of bioenergy [3]. Public parks, lawns, cemeteries and roads usually are surrounded by the grassland and overgrown with different species of trees, including leafy trees, so the leaf biomass can be collected from all of those areas. It is time to take care on the foliage and the grasses, e.g. on the grasses to be collected according to park maintenance activities plan. After harvesting often such biomass is stored for long periods for composting due to the lack of alternative use strategy, excess biomass must be burned in waste incineration plants. In the case of composting, added value can be created; however, greenhouse gas savings are not expected [4], which will be for incineration or gasification applications, when replacing fossil fuels.

One of the perspective biomass utilisation kinds is use of the biomass pellets as feedstock for combustion plants providing a high level of automation and utilisation. However, grass biomass, compared to wood pellets, has chemical and physic-mechanical properties not suitable for incineration [5; 6]. Extremely high ash content (up to $45 \%$ dry matter (DM) in leaves causes the combustion disturbance due to contamination of leaves biomass with the soil during its collection process [7]) and due to the high content of inorganic substances in leaves. The concentration of large amounts of chlorine $(\mathrm{CI})$, nitrogen $(\mathrm{N})$, sulphur $(\mathrm{S})$ contributes to formation of harmful gases $\left(\mathrm{HCl}, \mathrm{SO}_{2}, \mathrm{NOx}\right)$ and the sum of elements $\mathrm{K}, \mathrm{Na}, \mathrm{Zn}, \mathrm{Pb}$, etc. contributes to formation of particulates (PM) in gaseous 
emissions [8]. These elements and their interactions during combustion can be summarized up using the fuel indices [9] to help predict possible emissions, corrosion and pollution problems that could impose the restrictions to combustion plant operation. In addition, fresh grass biomass has high moisture content that is the limiting factor for the pre-treatment, drying and transportation of feedstock to biomass combustion plants. Another limiting factor for use of grass biomass as feedstock in combustion plants is the losses of organic matter and valuable plant nutrients $(\mathrm{C}, \mathrm{N}, \mathrm{S}$, etc.), so these nutrients are not returned in the natural nutrients cycle. Therefore, biogas production from grass biomass for energy purposes can be regarded as the best possible method for energy recovery from grasses without the above mentioned limitations.

Fossil energy resources are rapidly diminishing in the world. Therefore, it is necessary to use the renewable energy resources and in the first order, the different types of organic waste in the best possible way. If the organic wastes are stacked incorrectly, microbial degradation is ongoing and harmful gases release from biomass, including greenhouse gases. Gases escaping from the piles contain the valuable plant nutrients $(\mathrm{C}, \mathrm{N}, \mathrm{S})$ that lower the fertilisation value of the finished compost. Lot of biomass wastes and residues originate in the agricultural production process, and these can also be used for biogas production. In Latvia, 59 biogas plants are built and 56 are running in Latvia utilising a lot of different raw biomass materials. One of the most widely used raw material is the corn silage, since it is used both for biogas or fodder production in dairy farms [10]. However, some farmers' organizations have been influenced by the Ministry of Agriculture of Latvia resulting in acceptance of measures restricting the use of maize silage for biogas production recently. These Cabinet regulations are based on debatable assumption that arable land should to be used for food production predominantly. One of such measures of the Cabinet regulations repeals the subsidized excise tax allowance on diesel fuel purchase for farmers growing maize biomass for biogas production. The production of corn silage is expensive and, when the diesel fuel with excise tax is included in the price on diesel, the maize biomass production becomes unprofitable for biogas plants. Therefore, it is essential for biogas producers to find cheaper raw materials, e.g. grass and other herbaceous biomass. The grasses need to be collected and processed to the required condition, e.g. grass silage, hay, hay pellets, for use for energy production purposes.

Grasses (Poaceae) are grown to produce vegetative mass. The most important grasses for bioenergetics are canary grass (Phalaris arundinacea L.), cocksfoot grass (Dactylis glomerata L.), timothy (Phleum pratense L.), awnless brome (Bromus inermis Leyss.), fescue pastures (Festuca L.), ryegrass (Lolium L.) and meadow foxtail (Alopecurus pratensis L.). There are also wide lake areas overgrown with common reed (Phragmites australis Cav.) in Latvia [10].

The vegetative grasses can be used as fresh biomass for biogas production, but grasses also can be used for the preparation of various biofuels, e.g. in form of pellets or briquettes. Researchers in Denmark even doubled biogas production from straw and hay pellets, compared to that obtained from non-granulated biomass [11]. Grasses are the main component in plant cover of natural grasslands and cultivated meadows. Grasses are cultivated also in mixed agricultural crops, mixed crops include the papilionaceous plants as a prevalent component usually.

The purpose of this investigation is to find out if the yield of biogas and methane can be obtained from herbaceous pellets and from their co-fermentation with sunflower oil and molasses.

\section{Materials and methods}

Herbaceous (straw or grass) pellets with the diameter $8 \mathrm{~mm}$ and specific weight above $1 \mathrm{~g} \mathrm{~cm}^{2}$ (Fig. 1) were used in the investigation. The grass hay pellets were fabricated for animal feed. The main advantage of herbaceous pellets is that the pellets do not form a floating layer after immersion in a liquid (Fig. 2) substrate. Pellets absorb a large amount of liquid before complete disintegration in the substrate. The investigation method used was similar to that accepted in Germany [12].

The average samples were taken and the chemical compositions were determined in the Latvia University of Life Sciences and Technologies laboratory according to the standardized methodology ISO 6496: 1999.

The accuracy of the measurements was \pm 0.02 for $\mathrm{pH}, \pm 0.025 \mathrm{l}$ for gas volume and $\pm 0.1^{\circ} \mathrm{C}$ for temperature. The biogas analyses (content of $\mathrm{CH}_{4}$, carbon dioxide $\mathrm{CO}_{2}$, oxygen $\mathrm{O}_{2}$ and hydrogen 
sulphide $\mathrm{H}_{2} \mathrm{~S}$ ) were provided periodically. The amount of biogas production was investigated using laboratory equipment consisting of 32 bioreactors with volumes of $0.75 \mathrm{~L}$. Bioreactor volume is sufficient for digestion of substrates consisting of biomass particles in the size similar to the size of particles of biomass feedstock used in real biogas plants.Usage of numerous reactors providing replications within same group of bioreactors (having the same composition of substrates) ensures statistically reliable results.

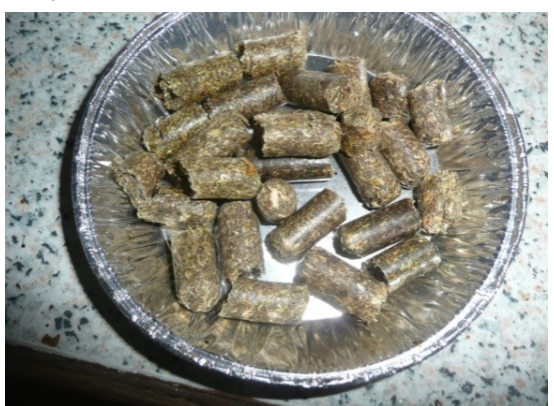

Fig. 1. Grass hay pellets

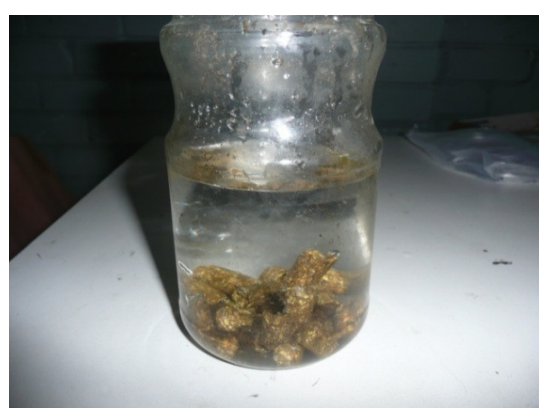

Fig. 2. Hay pellets do not float in liquid

Inoculums used for investigations were comprised of fermented cow manure that is the most frequently used base substrate (inoculums) in biogas plants in Latvia, therefore, the results of investigations obtained in small bioreactors at temperature $38^{\circ} \mathrm{C}$ can be scaled up for practical usage in real biogas plants operating at the same temperature.

Constant operating temperature $38^{\circ} \mathrm{C}$ was provided for substrates in two incubators (Memmert model). Bioreactors were also shaken to reduce the floating layer regularly.The anaerobic fermentation process took place in batch (single filling) mode and lasted until the biogas production ceases.

The dry matter was determined using the dryer-scales unit Shimazu at $105^{\circ} \mathrm{C}$, the organic matter content was determined by further processing of the sample in the oven (Nabertherm model) at $550{ }^{\circ} \mathrm{C}$ according to a special program. The gas composition (methane, oxygen, carbon dioxide and hydrogen sulphide content in the biogas) was measured using the gas analyser (GA 2000 model). Gas volumes were measured using gas bags, and normal gas volumes were calculated using the data on actual temperature and pressure. The scale (model Kern FKB 16KO2) was used for measuring of substrate weight. For pH measurements a pH meter (model PP-50) was used stationary. Every finished digestate was weighed, and dry matter, ash and organic dry matter content were determined.

\section{Results and discussion}

Study 1. Purpose of this study is to investigate the biogas and methane production from anaerobic fermentation of grass pellets.

The total amount of biogas and methane produced was estimated from summarized measurements of biogas and methane released from 16 bioreactors. Average results were calculated and summarized in tables and shown in Fig.s. The results of the raw material analysis are summarized in Table 1.

Table 1

\section{Raw material analysis}

\begin{tabular}{|c|c|c|c|c|c|c|c|c|}
\hline Reactor & $\begin{array}{c}\text { Raw } \\
\text { biomass }\end{array}$ & Weight, $\mathbf{g}$ & $\mathbf{p H}$ & $\mathbf{T S}, \boldsymbol{\%}$ & $\begin{array}{c}\text { TS, } \\
\mathbf{g}\end{array}$ & $\begin{array}{c}\text { ASH, } \\
\mathbf{\%}\end{array}$ & $\begin{array}{c}\text { DOM, } \\
\mathbf{\%}\end{array}$ & $\begin{array}{c}\text { DOM, } \\
\mathbf{g}\end{array}$ \\
\hline R1; R16 & IN & $500.0 \pm 0.2$ & 7.31 & 9.84 & 49.200 & 9.48 & 90.52 & 44.53 \\
\hline R2-R15 & GP & $20.0 \pm 0.001$ & - & 88.76 & 17.752 & 8.74 & 91.26 & 16.20 \\
\hline R2-R15 & IN + GP & $520.0 \pm 0.2$ & 7.32 & 13.07 & 67.952 & 10.63 & 89.37 & 60.73 \\
\hline
\end{tabular}

Abbreviations: TS - total solids; ASH - ashes; DOM - dry organic matter; GP - grass hay pellets; IN-inoculums

As it can be seen from the table, the raw materials of grass hay pellets have high dry matter and organic dry matter content. Grass hay pellets, after immersing in a liquid, quickly absorbed moisture and disintegrated in the liquid media, but did not form a surface layer in the upper part of the liquid, contrary to dry, not granulated hay forming the biomass layer in the upper part of the liquid.

This raw material, which contains a lot of organic dry matter, is well suited for biogas production. 
The yields of biogas and methane from grass hay pellets are presented in Table 2.

Biogas and methane production from grass hay pellets

\begin{tabular}{|c|c|c|c|c|c|c|}
\hline Reactor & $\begin{array}{c}\text { Raw } \\
\text { biomass }\end{array}$ & Biogas, $\mathbf{l}$ & $\begin{array}{c}\text { Biogas, } \mathbf{l} \cdot \mathbf{g}^{-} \\
\text {DoM }\end{array}$ & $\begin{array}{c}\text { Methane, } \\
\mathbf{\%}\end{array}$ & Methane, $\mathbf{l}$ & $\begin{array}{c}\text { Methane, } \\
\mathbf{l}^{-\mathbf{1}} \mathbf{\text { DoM }}\end{array}$ \\
\hline R1 & IN & 0.20 & N/A & 4.00 & 0.008 & N/A \\
\hline R16 & IN & 0.20 & N/A & 3.90 & 0.008 & N/A \\
\hline R2 & IN + GP & 10.50 & 0.648 & 53.68 & 5.637 & 0.348 \\
\hline R3 & IN + GP & 10.40 & 0.642 & 54.82 & 5.702 & 0.352 \\
\hline R4 & IN + GP & 10.60 & 0.654 & 53.28 & 5.648 & 0.348 \\
\hline R5 & IN + GP & 10.80 & 0.667 & 53.07 & 5.732 & 0.354 \\
\hline R6 & IN + GP & 10.90 & 0.672 & 53.24 & 5.803 & 0.358 \\
\hline R7 & IN + GP & 11.00 & 0.679 & 53.76 & 5.914 & 0.365 \\
\hline R8 & IN + GP & 11.20 & 0.691 & 53.11 & 5.948 & 0.367 \\
\hline R9 & IN + GP & 10.80 & 0.667 & 53.18 & 5.744 & 0.354 \\
\hline R10 & IN + GP & 10.70 & 0.660 & 53.20 & 5.692 & 0.351 \\
\hline R11 & IN + GP & 10.80 & 0.667 & 52.89 & 5.712 & 0.352 \\
\hline R12 & IN + GP & 10.90 & 0.672 & 53.31 & 5.811 & 0.359 \\
\hline R13 & IN + GP & 11.00 & 0.679 & 53.15 & 5.846 & 0.361 \\
\hline R14 & IN + GP & 10.70 & 0.660 & 53.48 & 5.722 & 0.352 \\
\hline R15 & IN + GP & 10.80 & 0.667 & 52.67 & 5.688 & 0.351 \\
\hline Aver. R2- & $\mathbf{1 0 . 7 9} \pm \mathbf{0 . 2 1}$ & $\mathbf{0 . 6 6 6} \pm \mathbf{0 . 0 1 3}$ & $\mathbf{5 3 . 3 4 \pm 0 . 5 1}$ & $\mathbf{5 . 7 5 7} \pm \mathbf{0 . 0 9 5}$ & $\mathbf{0 . 3 5 5} \pm \mathbf{0 . 0 6}$ \\
\hline R15 + STDEV &
\end{tabular}

Abbreviations: $l \cdot g^{-1}$ DOM - litres of gases produced per $1 \mathrm{~g}$ of initial dry organic matter in the raw material, GP - grass hay pellets, N/A - values not applicable for further calculations, as values from control reactors are substracted already from respective values of other bioreactors in this table.

Gas values measured from bioreactors with added biomass (R2-R15) are provided in Table 2 with already subtracted respective average value from the control reactors (R1; R16).

The obtained results were surprisingly good. Usually, pre-shredding of raw material significantly increases methane yields, as the hay pellets are composed from finely chopped grass biomass. The high biogas yield can be explained by the fact that the raw material was better distributed within the substrate and the anaerobic fermentation process was ongoing intensively due the better microbial access to the raw material, not forming the layer on the surface. Compared to other biomass, the methane yield is not high due to the high $\mathrm{C}: \mathrm{N}$ ratio in grass hay pellets biomass. This raw material contains a lot of organic dry matter, so it is well suited for biogas production. The yields of biogas and methane from grass hay pellets are summarized in Table 2.

Surprisingly good biogas yield was observed from grass hay pellets, perhaps, due to pre-shredding of the raw material before pelleting. This could be explained by the fact that the raw materials were better distributed within the substrate process and the raw material did not form a layer on the surface. Average specific volumes of biogas and methane from bioreactors with added grass hay pellets are shown in Fig. 3.

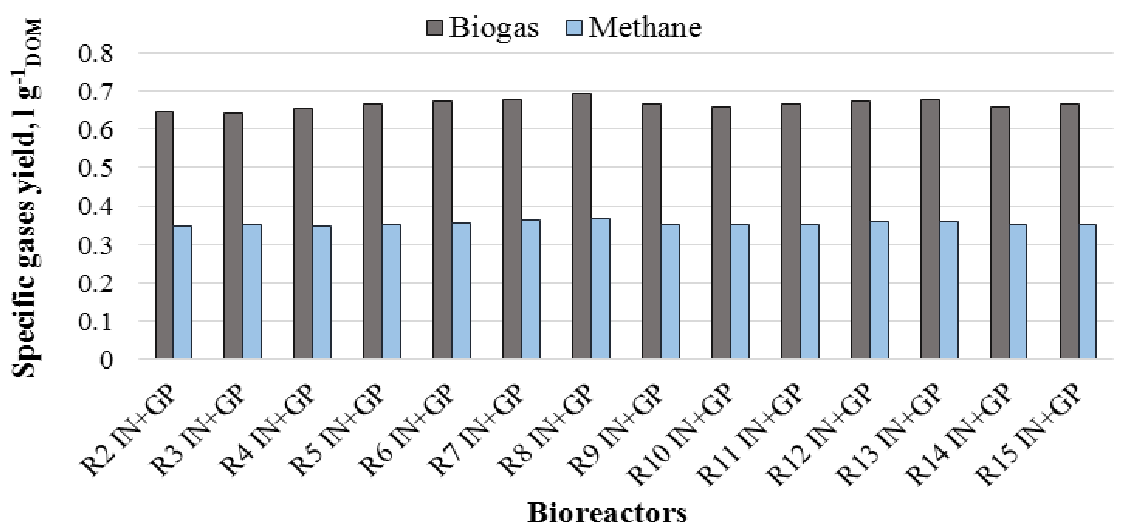

Fig. 3. Specific biogas and methane yield from grass hay pellets 
Study 2. Purpose of this study is to investigate the biogas and methane production from anaerobic fermentation of straw and grass pellets and from co-fermentation of grass pellets with sunflower oil or molasses.

The results of the raw material analysis are summarized in Table 3.

Table 3

The results of the raw material analysis

\begin{tabular}{|c|c|c|c|c|c|c|c|c|}
\hline Bioreactor & Raw material & Weight g & $\mathbf{p H}$ & TS \% & $\begin{array}{c}\text { TS } \\
\mathbf{g}\end{array}$ & $\begin{array}{c}\text { ASH } \\
\mathbf{\%}\end{array}$ & $\begin{array}{c}\text { DOM } \\
\mathbf{\%}\end{array}$ & $\begin{array}{c}\text { DOM } \\
\mathbf{g}\end{array}$ \\
\hline R1, R16 & IN & $500 \pm 0.2$ & 7.35 & 9.97 & 49.85 & 10.91 & 89.09 & 44.41 \\
\hline R2-R4 & SP & $20 \pm 0.001$ & - & 85.42 & 17.084 & 3.93 & 96.07 & 16.413 \\
\hline R2-R4 & IN + SP & $520 \pm 0.2$ & 7.35 & 12,87 & 66.934 & 9.13 & 90.87 & 60.823 \\
\hline R5-R8 & GP & $20 \pm 0.001$ & - & 88.73 & 17.746 & 8.76 & 91.24 & 16.191 \\
\hline R5-R8 & IN + GP & $520 \pm 0.2$ & 7.36 & 13.00 & 67.596 & 10.33 & 89.67 & 60.611 \\
\hline R9-R12 & SO & $4 \pm 0.001$ & - & 99.95 & 3.998 & 0.3 & 99.7 & 3.986 \\
\hline R9-R12 & IN + GP + SO & $524 \pm 0.2$ & 7.37 & 13.66 & 71.594 & 9.79 & 90.21 & 64.587 \\
\hline R13-R15 & MO & $4 \pm 0.001$ & - & 89.98 & 3.599 & 23.25 & 76.75 & 2.762 \\
\hline R13-R15 & IN + GP + MO & $524 \pm 0.2$ & 7.34 & 13.59 & 71.195 & 11.00 & 89.00 & 63.363 \\
\hline
\end{tabular}

Abbreviations: SP - straw pellets; GP - grass hay pellets; $S O$ - sunflower oil; $M O$ - molasses.

The methodology and the equipment used were the same as in the first study. Inoculums in the amount of $500 \mathrm{~g}$ were loaded in all reactors, $20 \mathrm{~g}$ of straw pellets were added in bioreactors R2-R4, 20 $\mathrm{g}$ grass hay pellets in bioreactors R5-R8, $20 \mathrm{~g}$ grass hay pellets and $4 \mathrm{~g}$ sunflower oil in bioreactors $\mathrm{R} 9-\mathrm{R} 12$, and $20 \mathrm{~g}$ grass pellets and $4 \mathrm{~g}$ of molasses were added in bioreactors R13-R15. In this study, the inoculum was composed from $50 \%$ of finished cow manure digestate and from $50 \%$ of finished digestate from the previous study (straw pellets with cow manure).

This fact explains the unusually high content of the dry matter in inoculums (IN), see Table 3 . The study also aimed to compare the yields from fermentation of straw pellets and grasses, but extraordinary biogas yield obtained from the straw pellets $(\mathrm{IN}+\mathrm{SP})$ exceeds the results from the previous study with straw pellets significantly. This evidence can be explained by the fact that biogas was produced also from substances in inoculums that were not degraded in the previous study. Such the evidence is not observed in bioreactors with added grass hay pellets (IN + GP) and in control bioreactors with inoculums (IN). Therefore, the results of this study from bioreactors with added straw pellets (IN + SP) cannot be used for comparison of straw pellets with grass pellets correctly.

Adding $4 \mathrm{~g}$ of sunflower oil or $4 \mathrm{~g}$ of molasses to the grass hay pellets results in increasing of the average methane yield by $29.0 \%$ or $8.9 \%$ from substrates with sunflower oil (GP + SO) or molasses (GP + MO) respectively, see Table 4. Relatively low methane yield increase was observed for grass pellets with added molasses (GP + MO), may be due to impaired quality of molasses (unfortunately, there was not accurate information provided from the molasses sample supplier).

Further calculations show that the specific methane yield obtained from the added sunflower oil (SO) or molasses (MO) was $0.870 \mathrm{l} \cdot \mathrm{g}^{-1}$ DOM or $0.566 \mathrm{l} \cdot \mathrm{g}^{-1}$ DOM, respectively.

Table 4

Biogas and methane production from biomass pellets

\begin{tabular}{|c|c|c|c|c|c|c|}
\hline Bioreactor & Raw material & Biogas, I & \begin{tabular}{|c} 
Biogas l'g \\
DOM
\end{tabular} & Methane, \% & Methane, I & $\begin{array}{c}\text { Methane } \mathrm{l}^{-\mathrm{g}^{-}} \\
\mathrm{DOM}^{-}\end{array}$ \\
\hline R1 & IN & 0.20 & N/A & 3.60 & 0.007 & N/A \\
\hline R16 & IN & 0.20 & N/A & 3.50 & 0.007 & N/A \\
\hline $\mathrm{R} 2$ & $\mathrm{IN}+\mathrm{SP}$ & 14.80 & 0.902 & 47.22 & 6.988 & 0.426 \\
\hline R3 & $\mathrm{IN}+\mathrm{SP}$ & 13.70 & 0.835 & 49.11 & 6.668 & 0.406 \\
\hline $\mathrm{R} 4$ & $\mathrm{IN}+\mathrm{SP}$ & 13.90 & 0.847 & 49.15 & 6.832 & 0.416 \\
\hline \multicolumn{2}{|c|}{ Aver. R2-R4 \pm STDEV } & $\begin{array}{r}\mathbf{1 4 . 1 3 3} \\
\pm 0.59\end{array}$ & $\begin{array}{c}\mathbf{0 . 8 6 1} \\
\pm 0.036\end{array}$ & $\begin{array}{l}\mathbf{4 8 . 3 2} \\
\pm 1.10\end{array}$ & $\begin{array}{c}\mathbf{6 . 8 2 9} \\
\pm 0.160 \\
\end{array}$ & $\begin{array}{c}\mathbf{0 . 4 1 6} \\
\pm 0.010\end{array}$ \\
\hline
\end{tabular}


Table 4 (continue)

\begin{tabular}{|c|c|c|c|c|c|c|}
\hline Bioreactor & Raw material & Biogas, 1 & 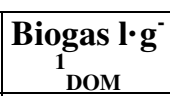 & Methane, \% & Methane, I & $\begin{array}{c}\text { Methane } \mathrm{l}^{-} \mathrm{g}^{-} \\
{ }_{\text {DOM }}\end{array}$ \\
\hline R5 & IN + GP & 11.10 & 0.686 & 53.35 & 5.932 & 0.366 \\
\hline R6 & $\mathrm{IN}+\mathrm{GP}$ & 11.40 & 0.704 & 51.14 & 5.822 & 0.360 \\
\hline R7 & $\mathrm{IN}+\mathrm{GP}$ & 10.40 & 0.642 & 51.4 & 5.343 & 0.330 \\
\hline R8 & $\mathrm{IN}+\mathrm{GP}$ & 10.60 & 0.655 & 53.74 & 5.694 & 0.352 \\
\hline \multicolumn{2}{|c|}{ Aver. R5-R8 \pm STDEV } & $\begin{array}{l}\mathbf{1 0 . 8 7 5} \\
\pm 0.457\end{array}$ & $\begin{array}{c}\mathbf{0 . 6 7 2} \\
\pm 0.028\end{array}$ & $\begin{array}{l}\mathbf{5 2 . 4 1} \\
\pm 1.33\end{array}$ & $\begin{array}{c}\mathbf{5 . 6 9 8} \\
\pm 0.256\end{array}$ & $\begin{array}{c}\mathbf{0 . 3 5 2} \\
\pm 0.016 \\
\end{array}$ \\
\hline R9 & $\mathrm{IN}+\mathrm{GP}+\mathrm{SO}$ & 16.80 & 0.833 & 56.08 & 9.421 & 0.467 \\
\hline R10 & $\mathrm{IN}+\mathrm{GP}+\mathrm{SO}$ & 18.40 & 0.912 & 58.81 & 10.821 & 0.536 \\
\hline R11 & $\mathrm{IN}+\mathrm{GP}+\mathrm{SO}$ & 16.10 & 0.798 & 53.44 & 8.605 & 0.426 \\
\hline R12 & $\mathrm{IN}+\mathrm{GP}+\mathrm{SO}$ & 16.90 & 0.836 & 46.28 & 7.822 & 0.388 \\
\hline \multicolumn{2}{|c|}{ Aver. R9-R12 \pm STDEV } & $\begin{array}{l}\mathbf{1 7 . 0 5 0} \\
\pm 0.968\end{array}$ & $\begin{array}{c}\mathbf{0 . 8 4 5} \\
\pm 0.048\end{array}$ & $\begin{array}{l}\mathbf{5 3 . 7 6} \\
\pm 5.38\end{array}$ & $\begin{array}{c}\mathbf{9 . 1 6 7} \\
\pm 1.281\end{array}$ & $\begin{array}{c}\mathbf{0 . 4 5 4} \\
\pm 0.063\end{array}$ \\
\hline R13 & $\mathrm{IN}+\mathrm{GP}+\mathrm{MO}$ & 13.50 & 0.712 & 53.45 & 7.216 & 0.381 \\
\hline R14 & $\mathrm{IN}+\mathrm{GP}+\mathrm{MO}$ & 13.40 & 0.707 & 55.29 & 7.409 & 0.391 \\
\hline R15 & $\mathrm{IN}+\mathrm{GP}+\mathrm{MO}$ & 13.10 & 0.691 & 54.67 & 7.162 & 0.378 \\
\hline \multicolumn{2}{|c|}{ Aver. R13-R15 \pm STDEV } & $\begin{array}{l}\mathbf{1 3 . 3 7 0} \\
\pm 0.208\end{array}$ & $\begin{array}{c}\mathbf{0 . 7 0 3} \\
\pm 0.011\end{array}$ & $\begin{array}{l}\mathbf{5 4 . 4 7} \\
\pm 0.94\end{array}$ & $\begin{array}{c}\mathbf{7 . 2 6 2} \\
\pm 0.130\end{array}$ & $\begin{array}{c}\mathbf{0 . 3 8 3} \\
\pm 0.007\end{array}$ \\
\hline
\end{tabular}

Note: Gas values measured from bioreactors with added biomass (R2-R15) are provided in Table 4 with already subtracted respective average value from control reactors (R1, R16).

Average specific volumes of biogas and methane from bioreactors with added straw pellets or grass hay pellets with oil and molasses are shown in Fig. 4.

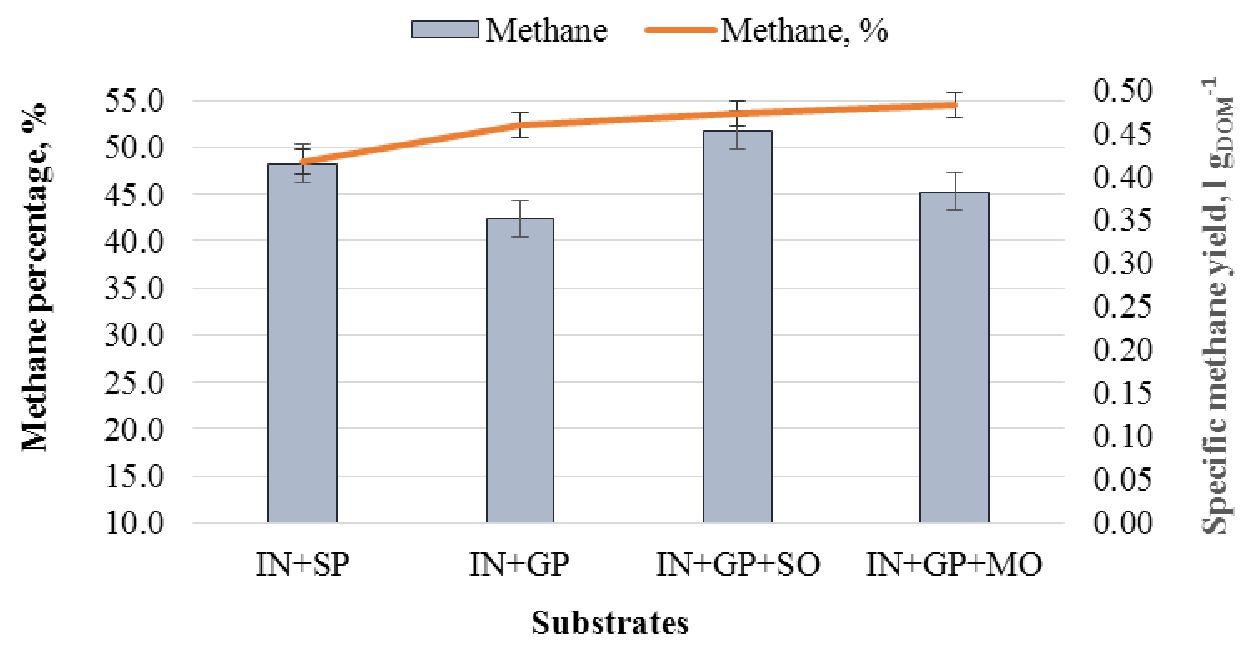

Fig. 4. Average specific methane yield and methane content in biogas from straw pellets, grass pellets, and from grass pellets co-fermentation with oil and molasses

The average percentage of methane from each bioreactor is shown in Table 4 . The lowest average of $48.3 \%$ was obtained from straw pellets, but the highest $54.5 \%$ from molasses. The average methane yield in the group of bioreactors with added sunflower oil was lowered by a very low value from bioreactor No.12, otherwise the average specific methane volume from sunflower oil may be even better compared to the average methane volume obtained from the group of reactors with added molasses.

\section{Conclusions}

1. Average specific biogas and methane yield obtained from grass hay pellets was $0.666 \mathrm{l} \cdot \mathrm{g}-1 \mathrm{DOM}$ or $0.355 \mathrm{l} \cdot \mathrm{g}-1 \mathrm{DOM}$, respectively.

2. Grass hay pellets do not form a floating layer after submersion in a liquid.

3. The average methane content in biogas from grass hay pellets was $53.3 \%$. 
4. If $4.0 \mathrm{~g}(16.7 \%)$ of sunflower oil or molasses is added to grass hay pellets, then the average methane content in biogas increases by $29.0 \%$ or $8.9 \%$, respectively.

5. The content of H2S throughout the study was relatively low in all bioreactors, and was slightly increased in the bioreactors with added sunflower oiL.

6. The results of the study show that grass hay pellets are good as raw materials for the production of methane.

7. Grass hay pellets can be used for co-digestion with sunflower oil, since a better methane yield was obtained and a more stable fermentation process provided.

8. Grass hay pellets can be a good raw material for co-fermentation with other wastes, e.g. molasses, fats, manures, etc. It would be necessary to first check the co-fermentation options in laboratory conditions to determine the best proportions.

\section{Acknowledgements}

This investigation was supported by the Latvian National Research Programme LATENERGI.

\section{LATENERGI}

\section{References}

[1] Atanasiu B. The Role of Bioenergy in the National Renewable Energy Action Plans: A First Identification of Issues and Uncertainties. Publication of the Biomass futures project (IEE 08653 SI2. 529 241), 2010, $22 \mathrm{p}$.

[2] Thrän D., editor. Smart Bioenergy. Springer International Publishing: Switzerland, 2015, 179 p.

[3] Kretzschmar J., Thrän D. Energy recovery from roadside vegetation. E-journal "Müll und Abfal", 11/2009, pp. 577-583. (In German).

[4] Bühle L., Hensgen F., Donnison I., Heinsoo K. etc. Life cycle assessment of the integrated generation of solid fuel and biogas from biomass (IFBB) in comparison to different energy recovery, animal-based and non-refining management systems. Bioresour. TechnoL.voL. 111, 2012, pp. 230-239.

[5] Prochnow A., Heiermann M., Plöchl M. etc. Bioenergy from permanent grassland - A review: 2. Combustion. Bioresour. TechnoL.voL. 100,2009, pp. 4945-4954.

[6] Piepenschneider M., Nurmatov N., Bühle L. etc. Chemical Properties and Ash Slagging Characteristics of Solid Fuels from Urban Leaf Litter. Waste Biomass Valorization, voL. 7 (3), 2016, pp. 625-633.

[7] Khalsa J., Döhling F., Berger F. Foliage and Grass as Fuel Pellets-Small Scale Combustion of Washed and Mechanically Leached Biomass. Energies voL. 9 (5), 2016, 16 p.

[8] Obernberger I., Brunner T., Bärnthaler G. Chemical properties of solid biofuels - Significance and impact. Biomass Bioenergy, voL. 30, 2006, pp. 973-982.

[9] Brunner T., Obernberger I. Fuel indexes: A novel method for the evaluation of relevant combustion properties of new biomass fuels. Energy Fuels. VoL.26, 2012, pp. 380-390.

[10] Dubrovskis V., Adamovičs A. Bioenergèetikas horizonti (Horizons of bioenergetics), Jelgava, 2012, 352 p. (In Latvian).

[11] Moler H., Hansen M. Briquettes of straw and dry grass double biogas production, FiB no. 47, 2014, 5 p.

[12] Kaltschmitt M. Methodenhandbuch, Leipzig, 2010, 93 p. (In German). 